\title{
EL DIOS DEL OTRO INICIO
}

\author{
Félix DuQue \\ Universidad Autónoma de Madrid
}

\begin{abstract}
RESUMEN. Tomando como punto de partida la última Fuge (juntura y fuga musical, a la vez) de los Aportes a la filosofia de Martin Heidegger, y yendo más allá de su letra, este breve ensayo se propone denunciar la coyunda de la civilización consumista y mercantilizada actual con una "explotación" pseudocristiana del dios. Al respecto, examina con la ayuda de Hölderlin las características de una divinidad atenta al sufrimiento y esperanzas de los mortales, "ayudando" a éstos mediante su falta y su fuga, siempre sida, custodiada en los documentos sagrados de la poesía. Se postula a este propósito una estrechísima cercanía entre la mortalidad humana y la latencia de lo divino, oscilante entre lo ya de siempre sido ( $\mathrm{y}$ refugiado en el poema) y lo que está al venir (anticipado en la palabra pensante).
\end{abstract}

Freno intentan poner a las casquivanas andanzas del heredero de $\mathrm{El}$ Caserío, una vieja zarzuela vasca de Jesús Guridi, las sensatas palabras de la novia destinada. A la dolida pregunta de aquél: "Anamari, ¿̇ú también / me condenas por vivir»?, responde una voz absolutamente moderna: «Por gastar tu juventud / sin provecho para ti». En esa voz habla la lógica de la producción. La juventud, flor de la vida, es un capital inicial que hay que saber emplear, un flujo constante que, lejos de disiparse, ha de revertir asintóticamente, y si fuera posible sin resto, en el sujeto, o sea en alguien sujeto a su propia cerrazón: a su sí-mismo (Selbst). Tal la idea de provecho. En el tiempo se prende lo ente, transformado por la elaboración técnica en producto... de asimilación. La aurea catena entium es hoy una cadena de alimentación. El gasto queda bien empleado cuando se congela y petrifica en propiedades inmiscuidas ya en el hombre como una prótesis, haciendo así de él un cyborg. un organismo cibernético. Lo ajeno queda eliminado, sea por excluido, sea por consumido. Bien es verdad que al punto aparece otra cosa que, por de pronto, no se deja consumir, asimilar sin ardid: la astucia, la List de la 
razón se convierte así en condición de posibilidad de toda Leistung, de toda producción con rendimiento. De este modo, el provecho propio (Eigennutz) se extiende a un sí-mismo intercambiable, mostrenco y neutral: ni uno ni otro, sino cualquiera, tan "cualquiera", tan indistinto como para permitirme pensar - y pensarme- como si yo - a su vez, un "yo" cualquiera- estuviera en su lugar. "Pensar en el puesto (Stelle) de cualquier otro»: tal el modo liberal de pensar, alabado por Kant ${ }^{1}$, hasta el punto de hacer de esa máxima el eje de la amabilidad de su religión racional. En efecto, si amar es aceptar libremente entre las propias máximas la voluntad de otro ${ }^{2}$, tal aceptación es posible y deseable porque ese otro -idealmente, el Cristo- es un "amigo del hombre", más aún, porque es el prójimo (Mitmensch) por excelencia, cuya voz — como la de la sensata Anamari- habla directamente al corazón de los hombres, incitándolos a cumplir su propia voluntad; una voluntad, claro está, bien entendida (woblverstanden, como dice Kant), a saber: sugiriéndoles esa voz cómo tendrían que comportarse ellos mismos por su libre voluntad, "con tal de que hicieran examen de conciencia como es pertinente" (gehörig, tentado estaría yo de traducir: "como Dios manda»). Así se cumple la función del cristianismo, según Kant: «fomentar el amor al negocio (Geschäft) de la observancia del deber en general" (ibid.).

Se trata, en efecto, de un negocio. ¿A quién pertenece? ¿Quién dicta la pertinencia, la Zugehörigkeit? ¿Acaso Dios? Sólo que: «Esta idea de un soberano moral del mundo es una tarea propuesta a nuestra razón práctica. A nosotros no nos importa tanto saber lo que Dios sea en sí mismo (su naturaleza), cuanto lo que él sea para nosotros, en cuanto seres morales" ${ }^{3}$. Un dios, pues, a la medida del hombre: no de uno concreto, sino de cualquiera, en cuyo puesto (Stelle) pueda ponerme sin dificultad porque, dentro del "dispositivo" (Gestell) en el que la humanidad se emplaza (sich stellt), "para nosotros", ahora, Dios es el trasunto (Ebenbild) de nuestra propia intercambiabilidad. Feuerbach bien podría tener razón. Sólo que esa razón conduce a la irrelevante mediocridad de lo "políticamente correcto", como ya advertía Martin Heidegger en 1927: «en este modo de ser [el de "cualquiera", Man; F.D.] es el Dasein un ens realissimum, en caso de que se entienda "Realität" como ser a la medida del Dasein" ${ }^{4}$.

1 I. KANT, Kritik der Urteilskraft $\$ 40 ;$ Ak. V, 294; cf. Anthropologie in pragmatischer Hinsicht $\$ 59 ; \mathrm{VII}, 228$.

${ }^{2}$ I. KANT, Das Ende aller Dinge; VIII, 338.

3 I. KaNT, Die Religión, innerhalb der Grenzen der blossen Vernunft, VI, 139.

${ }^{4} M$. HeIDEgGER, Sein und Zeit $\$ 27$. Tubinga $1972^{12}, 128$. 
Con todo, es el propio Kant el que reconoce la insatisfacción suscitada por este uso inmanente de la razón. Sorprendentemente, el anciano, a sus setenta años, deja ver de soslayo y como un fogonazo lo más íntimo de su sentir: denn die Vernunft.. hat auch ibre Geheimnisse ("pues la razón - dice- tiene también sus secretos») $)^{5}$ ¿ ¿Cuáles son esos misterios? Intentemos sondearlos, preguntándonos: si la razón inmora en el pasado y allí permanece (immanens), ¿ por qué le tienta la trascencencia?, ¿por qué quiere ir más allá de sí? Al menos, algo cabe apuntar: el hogar, el tópos cordial o Heim de la razón no podrá darse al modo de esa coincidencia moderna, de esa coincidencia entre pasado y presente; una coincidencia que pretende prolongarse, desmesuradamente, en un tiempo perdurable (Fortdauer) en el que ya no pase nada... salvo el propio pasar inocuo del mismo. No sentir, ni pensar... sólo retenerse: ser si-mismo. ¿Para qué? La humana existencia se vacía en lo ente, esperando su restitución a partir de la elaborada estofa (Stoff) de lo sensible. Mas la característica manipulable de lo sensible, more mathematico pertractatum (no se olvide que pertractare significa "examinar" y "manosear"), es extensio: pura dispersión técnicamente regulada, un estar fuera de sí que contagia al hombre que con ella comercia, aunque, por más que éste haga, siempre quedarán restos inasimilables, desechos; literalmente, excrementos.

Por eso, los viejos dioses griegos se abstienen de alimentarse de sólida comida. Su conservación se debe a fluidos puros: néctar y ambrosía, sin eliminación. Perfectos servomecanismos, asimilación sin desechos: perpetuum mobile. Mas ¿qué es la ambrosía sino la negación de la muerte, de la negra sangre (brótos) que brota de la herida del tiempo y hace del hombre un mortal (brotós)? Y justamente por ello, al dios le hace falta el mortal, necesita del sacrificio y ofrenda (Opfer) de su sangre, así como del humo de las víctimas propiciatorias. Su vida, la vida del dios, es la negación, y más: la recusación (Verweigerung) de la inmortalidad para el hombre. Es el recuerdo de una falta, de una necesidad (Not) lo que hace de nosotros seres $e$-sistentes: es, en definitiva, el recuerdo de que no somos dioses. Mas también a ellos, los siempre solamente "eternos" ${ }^{6}$, les hace falta el tiempo del hombre para manifestarse a su través, porque ellos son los faltos-de-futuro (Zukunftlosen).

Los dioses no han huido de la tierra, de los hombres y las cosas, por una maquinación humana, o en virtud de un desinterés «mundano" por parte de los

${ }^{5}$ Das Ende... VIII, 335.

${ }^{6}$ M. HeIDEGGER, Beiträge zur Philosophie (en lo sucesivo BPh). G.A. 65: 6. 
hombres. Los dioses son, por siempre, «huidos» (entflohene). Su vida es su fuga de la vida de los hombres. También para echar de menos a lo divino que nos falta se precisa, ciertamente, de una transformación de la cosa presente - vorhanden, a la mano- en sagrado espacio-de-juego-del-tiempo (Zeitspielraum) en el que puedan medrar obra, poema y ofrenda. Sólo allí puede crecer el recuerdo... no del Dios único, idolátricamente identificado con el ser como presencia constante - nunc stans-, sino de lo divino como abismo del tiempo. Tal es la tarea liminar de los Aportes a la filosofia: "Llevar este olvido en cuanto olvido, mediante un recuerdo, al destello previo (Vorschein) de su oculta potencia, y hacer que brille allí el sonar del eseyer (den Anklang des Seyns)»"

No se trata pues de rescatar lo ente del olvido del ser, de su abandono (Verlassenheit) por parte de éste, sino de hacer la experiencia misma del olvido. Con un verbo prodigioso, fuera de lo común (ungeheuer), lo ha expresado Heidegger: entwachen. No despertar de un mal sueño, para ver al dios cara a cara, sino un "estar desvelado" que es, ya de por sí, un «des-velar", un abandonar la vela, la vigilia: como si dijéramos, un dejar de estar vigilante, un "bajar la guardia», dejándose ir. Gelassenheit. «El pensar - dice Heidegger - [...] es de una parte un despertar del olvido del ser... mas, en cuanto tal despertar (Erwachen), es, por otra parte, no un cancelar (Tilgen: contra Hegel y su Tilgen der Zeit, pues: F.D.) el olvido del ser, sino un emplazarse en él y un estar (Stehen) dentro de él. Así, el des-velar del olvido del ser - un desvelar que tiene por fin el ir a ese olvido (zu ibr) - es el des-velar (Entwachen) en el acaecimiento propicio (Ereignis)" ${ }^{8}$. El Ereignis, en el que cabe "bajar la guardia», dejar de maquinar, es el «entre» (Zwischen), que está en medio (inmitten) del paso fugaz (Vorbeigang) del último dios y la historia de los hombres, al igual — pero sensu contrario- que el árbol de los desechos del cuento del Zend-Avesta-elogiado por Kant en El fin de todas las cosas - se hallaba en medio (mitten) del jardín del Edén.

Recordemos el relato. El paraíso estaría plantado en el cielo, con árboles comestibles de perfecta digeribilidad, hasta el punto de que los exiguos residuos de la comida se evaporaban sin rastro, durch unmerkliche Ausdïstung. Sólo uno, tentador y central - tentador por constituir el centro, el kéntron del Jardín-, ofrecía

7 BPh., 107.

${ }^{8}$ M. HeidegGer, Protokoll zum "Zeit und Sein". (En Zur Sache des Denkens. Tubinga, 1969, $32)$. 
frutos parcialmente indigestos, de modo que los excrementos de nuestros primeros padres no eran en este caso, por desgracia, susceptibles de eliminación aérea e imperceptible. Por eso, la ingestión primera de esos frutos representó, también por vez primera, e irrevocable, la mácula de un excremento indisponible, de un Abfall irrecuperable por vía aérea, «espiritual», diríamos. Así que, para no manchar el cielo con esas sobras, un Ángel expulsó a nuestros pecadores padres de ese celestial Jardín, hasta entonces impoluto, y los depositó en su futura morada: esta nuestra tierra, así definida: «Éste es el vertedero (Abraum) del universo». Desechos, expulsión, estar de más: en verdad, los frutos de aquel árbol sabían a muerte. Pero precisamente por eso - podemos colegir nosotros, los mortales-, por eso era necesario comer de él, para que - a través de la expulsión - se abriera un espacio libre, dejando así ser, al mismo tiempo, a la red que hace del Hombre primigenio, del Urmensch, simples hombres capaces — sin embargo, y nada menos- de experimentar el sufrimiento y la muerte, mientras que, a la inversa, los arrogantes, insípidos e indoloros dioses - Elohim del inicio- dejaban, con su retirada, abierta la posibilidad de que llegara a ser al último dios, dejaban que se desvaneciera su propio ser para que, al fin, sólo quedase pendiente (bleibt... aus) el dios venidero.

Ese «dejar ser» a la falta en el recuerdo, ese avizorar aquello que nos falta y que nos constituye como seres mortales, como aquellos que guardan las distancias de lo divino y así lo dejan ser... a distancia - es en efecto un entwachen, un zafarse a la vigilia y a la vigilancia para hacer que se revele la Vergessenheit: no un «olvido" del que fuera culpable el hombre, y que se remediaría románticamente gracias al poeta o al pensador que nos "despertara" (la filosofía está llena de "despertadores» de sueños más o menos dogmáticos). No: esa Seinsvergessenheit tendría como correlato, en nosotros, lo que su etymon precisamente indica: un "soltar la presa" (ver-gessen), como se ve aun con mayor claridad en la expresión inglesa correspondiente: to forget, que remite a la raíz ${ }^{*}$ ghend (presente en el latín apprehendere, apresar). Y ello significa, para nosotros los hombres ( $\mathrm{y}$ ello nos significa a nosotros, en cuanto hombres): No tratar a las cosas como ocasiones de un concepto, de una captación y un "echar mano" (ergreiffen), sino dejarlas ser... sobre el trasfondo de lo Abierto: un dar tiempo al tiempo, madurando (zeitigen) las posibilidades de las cosas como recuerdo de la ausencia de dios. En esta contención (Verbaltenheit) que es la Grundstimmung, el acorde de fondo o bajo continuo que preside la preparación del "otro inicio" ${ }^{9}$, quien así se contie- 
ne y com-porta (sich verhaltet) no lo hace en vista de la conservación (Erhaltung) de una vida, o de un alma (negotium salvationis), que para el caso lo mismo da, sino en favor de la guarda del silencio (Verschweigung), por mor de la suprema ofrenda, que es al mismo tiempo e indisolublemente el supremo desecho: la abnegación del individuo al aprestarse al dios que viene, al dios que está al venir, según se lee en las huellas del menesteroso e indigente, del otro al que yo hablo y salvo, mientras abandono en cambio intereses y vida propios como inmundicia capaz - sólo entonces, sólo por ello- de brillar con más fuerza que todas las cosas mundanas: «el cosmos más bello, como basura (sárma) esparcida al azar" ${ }^{10}$. Pues saberse mortal es saber sacrificarse: dar lugar al Dios que viene... dibujado, señalado en las huellas del extraño, del extranjero: del lejano que apela.

Y es precisamente en este lugar, en el Mitdasein que del ser brota (un "seren-convivencia" que nada tiene que ver con pueblos elegidos o pétreas razas excluyentes, sino que es, muy al contrario, la flor de la apatridia), es allí donde se anuncia según creo - yendo a través de Heidegger más allá de Heidegger- die Zukunft des Herrn. No "la venida del Señor", como pide el sentido de la versión luterana de 1 Tes 4, 15, sino "el estar por venir del Señor»: el Señor como futuro. Un dios que consiste en estar viniendo, y que nunca llegará a hacer acto de presencia, porque él es el futuro absoluto, el punto de fuga desde el que se disipan en el recuerdo los dioses huidos, al igual que nosotros llegamos demasiado pronto ( $z u$ früh) para el eseyer $(S e y n)^{11}$. Ello no significa, en modo alguno, que hayan de venir después otros hombres, en los que finalmente se acabará el poema y la condensación (Gedicht) del eseyer (Seyn). Cuando Heidegger se refiere a los advenideros (die Zu-künftigen), no mienta en modo alguno con ese término a los hombres del futuro. Al contrario, desde un punto de vista óntico y de sentido común, se trata de hombres del pasado: de muertos, y aun — por su locura- de muertos en vida, como Nietzsche o como Hölderlin. Pero en verdad, ellos no aparecerán en el futuro (Zukunft), ni tampoco han desaparecido en el pasado, porque aquí no se juega a las apariencias ni a las apariciones: no se trata de espíritus ni de fantasmas (revenants), porque ellos no "vuelven a venir», no volverán a estar con nosotros... dado que nunca se fueron, sino que, en su palabra floreciente, están-siendo-sidos. Bucle del tiempo extático: sólo die Gewesenden pueden ser die

10 Heráclito, Diels-Kranz 22 B 124.

"Aus der Erfahrung des Denkens. G.A. 13, 76. 
Zu-künftigen, porque sólo ellos tienen la capacidad, amando (vermögen), de preparar lo divino, de aprestarse a la acogida de esa región que, como ellos, ad-viene sólo en su estar-pendiente. Sólo ellos dejan que en sus palabras, como flores, constantemente se presienta lo que falta, lo que nos aguarda, porque sólo ellos guardan el «estar al venir» (zu... kommen) del dios. Por eso ellos -como ejemplo máximo de ser-hombre-en-el-limite, en el umbral entre lo sagrado y lo profano- son capaces de ofrendar su vida en el sacrificio (arte, poesía, pensamiento) que deja abierto, inminente, lo que ad-viene. Por eso son $Z u$-künftigen ${ }^{12}$.

Las señas del dios pendiente que los advenideros-sidos ofrecen a los hombres para que custodien esa "falta" tienen su lugar en la sede instantánea (Augenblicksstätte) dispuesta por aquéllos en favor de la apertura del Da del eseyer (Seyn): un Da-Seyn único, irrepresentable, supremamente ajeno y extraño (befremdlich), un existir que es un resistir y un desistir: la esencial ocultación de sí (en cuanto renuncia -interpreto- a toda "seña de identidad», a todo hecho diferencial y excluyente: el Daseyn extraño en el que todos los extraños - todos los recíprocamente extranjeros- hallan acogida). En esa estancia (Stätte) se juega —como antes se apuntó- la decisión "sobre el 'quedar pendiente' (Ausbleiben) y el 'estar al llegar' (Ankunft) de los dioses" " ${ }^{13}$. Adviértase, a este respecto, que Heidegger no presenta una alternativa (digamos, entre la ausencia y la presencia de lo divino), sino una conjunción, una coyuntura o Fuge: los dioses están al llegar albergándose en su "quedar pendientes", al igual que el ser se da bajo la guarda del olvido (del olvido de Sí, o sea: de toda imposición identitaria). Por eso, paradójicamente, es la Ewigkeit del dios último (que es a la vez e indisolublemente el punto de fuga de los dioses huidos) un paso fugaz: Vorbeigang, o mejor un «estar de paso" (como la stásis divina, a la que corresponde la Stätte humana): una inminencia que nunca llega, ni en nuestra vida (porque entonces es siempre aún "demasiado pronto" para ello), ni en nuestra muerte (pues que entonces habrá sido ya demasiado tarde).

La idea de un contra-tiempo como un "pasar de largo", ha sido recogida a mi entender por Heidegger de tres fuentes, dos de las cuales sigue, mientras rechaza la otra, aun reteniéndola como estímulo en la ardiente controversia

${ }^{12}$ Cf. BPh., 395-399.

13 BPh., 252. 
(Auseinandersetzung). La única fuente explícita es Hölderlin: «So ist schnellvergänglich alles Himmlisches ${ }^{14}$. Heidegger dilucida (erläutert) así estas palabras: «Pasar (Vergehen) no significa aquí perecer (zugrundegehen; pues, ¿a qué fondo iría el dios?, F.D.), sino pasar fugazmente (vorbeigehen), no permanecer, no estar ahí, asistiendo (anwesend) continuamente; es decir, y según la cosa: estar esenciando como lo que está siendo sido (wesend als Gewesendes), estar asistiendo a un envite que viene (kommenden Andrang). Es, pues, la contraesencia (Gegenwesen) de la alétheia griega, su corazón olvidado: la léthe: «Este campo del ocultamiento está opuesto a toda physis. La léthe no permite ningún phyein, ninguna eclosión ni proveniencia (Aufgehen und Hervorkommen)" ${ }^{15}$. Mas también por el lado de los mortales se entiende que lo celestial pase fugazmente. En efecto, si no fuera por la laudatio del poeta y del pensador, que sienten la pérdida, el dios permanecería, o bien manifiesto como una Cosa entre las cosas, por más que fuera la suprema (Ens summum), o bien sumergido en la sombra, en el «No" en que él, pendiente, persiste, sin que su falta llegara a ser experimentada por los hombres. Que sólo en la palabra del poeta se guarda y custodia en la sacra memoria el paso fugaz de lo divino, «rozando apenas las moradas de los hombres" ${ }^{16}$. Por eso, «el largo pensar-acordándose (Gedenken), el conservar en el recuerdo, es el modo en que, por así decir, se despliega la cercanía de los dioses» (ibid.).

La segunda fuente (inconfesada, mas documentable) proviene de la Biblia luterana, y de nuevo del Segundo Libro de Moisés (nuestro Éxodo). Bien puede decirse que esta narración judaica —para escándalo o paradoja, como se quiera- esconde la almendra de las crípticas alusiones al último dios de los Aportes a la filosofia (y aquí es importante recordar los años de elaboración de la obra: 1936 a 1938). Dios ha entregado a Moisés en el Sinaí las primeras Tablas de la Ley, el Decálogo: unas tablas - para nosotros, hombres- aún más ignotas que la cosa en sí kantiana, ya que Moisés las rompió en el monte. (¿Qué habría en ellas escrito?, ¿'lo mismo que en las conocidas por nosotros?; y el mensajero, ¿no tuvo siquiera la curiosidad de leer su contenido, antes de hacerlas pedazos?). En efecto, como es sabido, el pueblo había dejado de esperar ya la venida del envia-

${ }^{14}$ Vid. M. HeIDEGGER, Hölderlins Hymnen "Germanien" und "Der Rhein". (WS 1934/35: G.A. 39, 111).

${ }^{15}$ M. Heidegger, Parmenides. (WS 1942/43: G.A. 54, 176).

${ }^{16}$ WS 1934/35: G.A. 39, 111. 
do (¿cuánto puede durar la fe en algo o alguien que «está al venir»?), y desatendido las señas. Confiado en su Notlosigkeit, en su ausencia de cuidados, el pueblo forja un becerro de oro, fundiendo cuanto de valor tenían los judíos (esto es: degradando lo tesaurizado, las obras en las que latía el recuerdo de la falta, y convirtiendo el magma resultante, el producto, en una cosa presente, a la mano: vorhanden, a la que poder adorar por ser producto suyo - así ocurriría también con el dios cristiano, "construido" como ídolo alienante al decir de Feuerbach... y del propio Heidegger-). Indignado, Moisés rompe las tablas y se prepara para acoger, como advenidero ( $Z u$-kunftiger), la nueva Ley por venir. Sin embargo, ha de renunciar a la visión de Dios (¿gozó acaso de ella la vez primera?), limitándose a oír su voz. Pero solicita, al menos, ver su «apariencia», su dóxa (según la versión griega de los LXX), para que su pueblo le crea (juna creencia... por lo visto y en lo visto, como si el ojo popular fuera el juez y a la vez el fruidor de su ídolo!). En Lutero, la dóxa (latín gloria) es la Herrlichkeit de Dios ${ }^{17}$ : la señal que daría cuenta de su dominio, de su señorío. Y por ende, el infinito fuego abrasador de todo lo terreno. De ahí la divina respuesta negativa: «Mi faz (Angesicht) no la puedes ver; pues ningún hombre que me vea seguirá viviendo" ${ }^{18}$. Las palabras que en el texto sagrado vienen a continuación pueden sorprender a quien no tenga idea de la sólida formación en la hermenéutica de la Escritura con que el Heidegger de los años veinte se pertrechó. Para nosotros - latinos que no leemos la Biblia en alemán - podría parecer incluso, en un hysteron próteron, que esos términos son heideggerianos: tan acuñados han quedado por su uso filosófico. Dios dice en efecto a Moisés: «Mira, hay un espacio junto a mí (es ist ein Raum bei mir); ahí (da) has de quedarte de pie (stehen), sobre la roca. Ahora bien, cuando pase por delante mi gloria (meine Herrlichkeit vorïber gehet), dejaré que te yergas en la hendidura de la roca (in der Fessenkluft) y extenderé mi mano sobre ti hasta haber pasado" ${ }^{19}$. Es verdad que el término utilizado por Heidegger es Vorbeigehen y no Vorübergehen (siguiendo así al Hölderlin de Versöhnender, der du nimmergeglaubt: «Mas cuando un tiempo ha pasado (vorbei ist), ellos [los hombres] lo saben": saben, en efecto, lo que le ha acaecido al dios). Mas Heidegger utiliza esos dos términos como sinónimos - de acuerdo por demás con el uso corriente-. Por ejemplo, en el Curso de 1934/35 sobre Höl-

${ }^{17} 2$ Mose 33, 18. En Die Heilige Schrift... nach der deutschen Übersetzung Dr. Martin Luthers. Colonia 1863.

18 Mose 33, 20.

192 Mose 33, 21-22: cf. 34,6. 
derlin ambos aparecen juntos: gerade das Vorbeigehen, se dice, e inmediatamente después: im $\mathrm{Nu}$ des Vorübergangess ${ }^{20}$.

Importante es hacer notar que el espacio que está cabe (bei) el Dios mosaico es una roca hendida, es decir: que el Da de la hendidura (Zerklïftung, según la terminología de los Beiträge) es el que permite erguirse a Moisés (y, en general, al hombre), a partir de un fondo abismático. Ahora bien, en el parágrafo 157 de los Beiträge puede hallarse, sin forzar en absoluto el sentido del texto, una clara tra-ducción, una transposición del pasaje bíblico: «la hendidura del eseyer (Seyns) - se dice allí- puede llegar por vez primera a pregunta cuando la verdad del eseyer como acaecimiento (Ereignis) arroje luz (aufleuchtet), o sea cuando alumbre como eso de lo que el dios precisa, en tanto que el hombre le pertenece" ${ }^{21}$.

Al dios le hace falta el campo de su manifestación: él precisa del eseyer (Seyn); o como se diría en alemán, exactamente con el mismo verbo: al dios le hace falta (braucht) el Seyn. Mas ese campo está surcado, hendido por la «unicidad de la decisión en favor de la vía más corta y abrupta "22. Esa vía más corta es la del humano "estar a la muerte" (zum Tode sein): el soportar el litigio entre tierra lo ciego y desmedido - y mundo (en obras posteriores de Heidegger: el cielo) - lo abierto que da la medida - . Este juego mortal acota el campo en un espacio-de-juego-del-tiempo (Zeit-Spiel-Raum): correspondencia al instante, en cada caso di-ferida, de la instantánea congelación del tiempo. Sólo que, ahora, son estos fogonazos decisivos los que engendran al tiempo mismo: un tiempo, una larga historia, en la que las cosas dejan de ser y estar disponibles. El difícil pensamiento heideggeriano sobre la hendidura del eseyer (Seyn) se levanta, enigmático, en estas palabras, en las que se recoge a mi ver toda la temática de los Beiträge: "Todo decir relativo a la hendidura es una palabra pensante en busca del (zum) dios y dirigida al (an) hombre, yendo al estar-ahí (in das Da-sein) y, por ende, al litigio de mundo y tierran ${ }^{23}$.

Por último, la tercera fuente (igualmente tácita) relativa al Vorbeigang del dios se halla en el Also sprach Zarathustra nietzscheano. Si en 1934/35 habia con-

\footnotetext{
20 WS 1934/35: G.A. 39, 111; líneas 21 y 23, resp.

$21 B P h ., 279$.

22 BPh., 408.

23 BPh., 280.
} 
fesado Heidegger que a nosotros los hombres no nos está permitido «comenzar por el inicio», ya que "eso sólo lo puede un dios" ${ }^{24}$ —una concepción conscientemente opuesta, pues, a la defendida por Hegel en su Lógica-, pocos años después llega incluso Heidegger a dar nombre a tal inicio: se trata de la esenciación (Wesung) del ser mismo ${ }^{25}$ : de nuevo, un término más cercano a la teología cristiana (en claro trasunto de la kénosis del Evangelio de Juan) que a la filosofía tradicional, con la fundamental salvedad de que «la esenciación del eseyer no es el último dios, sino que funda la acción de salvamento (Bergung) y, por ende, procura la creadora custodia del dios, el cual diviniza de parte a parte (durchgottet), en cada caso, en obra y sacrificio, en acción y paso" ${ }^{26}$. Pero si Heidegger puede ahora osar acometer el inicio de la preparación para el pendiente advenir del dios, compaginándose (sich Fugend) ese Adviento con el inicio mismo (esto es: con el desgarramiento o hendidura del ser, con su carácter de $\mathrm{No}-\mathrm{Nicht-}$ haftigkeit-; con la recusación -Verweigerung - en suma de las cosas como "causas"), si se ve ahora - insisto- facultado para hacerlo, ello se debe, según creo, a que han existido advenidores (que siguen «siendo sidos») que han sacrificado vida y pensamiento en pro de esa preparación. Para Heidegger, estos cantores - Hölderlin y Nietzsche- de la huida y la ausencia de los dioses son advenideros porque «incluso en su existencia y en su obra fueron hasta el final», $y$ ello sólo porque «el inicio hizo valer su violencia sobre ellos, y fueron así elevados a lo Grande" ${ }^{27}$. Pues bien, en la tercera parte del Zarathustra brilla un extraordinario parágrafo: Vom Vorübergehen ${ }^{28}$. Allí el necio (Narr), el mono de Zaratustra, remeda sarcásticamente - sans le dire, claro está- el famoso final de la Fenomenología hegeliana, con los versos - modificados- de Schiller. Recuérdese:

\section{nur aus dem Kelche dieses Geisterreiches \\ schäumt ihm seine Unendlichkeit. ${ }^{29}$ \\ [sólo del cáliz de este reino de espíritus \\ le espumea su infinitud].}

\footnotetext{
${ }^{24}$ WS 1934/35: G.A. 39, 4: «mit dem Anfangen anfangen».

BPh., 58.

BPh., 262.

WS 1942/43: G.A. 54, 126.

${ }^{28}$ F. NIETZSCHE, Also sprach Zarathustra (en lo sucesivo: AsZ). Ed. Schlechra II, 699-702.

${ }^{29}$ G.W.F. Hegel, Phänomenologie des Geistes. G.W. 9, 434.
} 
Pues bien, en Nietzsche, el necio - -ese despreciable espíritu de la venganza- insta a gritos a Zaratustra para que no entre en la gran ciudad, ya que dice, uniendo así donosamente al Witzling persa recordado por Kant y al noble Schiller recordado por Hegel-, esa ciudad sería der grosse Abraum («el gran vertederon), el vertedero wo aller Abschaum zusammenschäumt («donde toda escoria se acumula»; o, más precisamente: «allí donde toda la espuma desechada de las cosas espumea de consunom). ${ }^{30}$ Así pues, la gran ciudad sería la hez de la realidad, el inmundo lugar donde se vierten los desechos. $\mathrm{Al}$ respecto, la actitud de Zarathustra no deja de ser significativa: por un lado, zahiere al necio por no haber seguido su ejemplo y huido de la ciudad, en lugar de pretender lucirse en ella y contra ella; mas, al cabo, extiende su condena también sobre ésta. Pues, sentencia: wo man nicht mehr lieben kann, da soll man — vorübergehen! ("jallí donde ya no se puede amar, se debe... pasar de largo! ${ }^{31}$ ).

No es ésa, empero, actitud conveniente para Heidegger (ni para Hölderlin —que por ello es más «ad-venidero" que Nietzsche, según se advierte explícitamente en los Beiträge-; y aún diríamos que tampoco lo es para el mismo Moisés, el cual no deja de regresar junto a su pueblo). Pues es cierto que el dios no puede sino pasar fugazmente por la ciudad; pero ese instante decisivo, el instante del Aus-trag, es recogido por el poeta o el pensador, el cual, aunque no dispone de su propio fondo o kéntron, guarda en su entraña perforada - perforada por el kéntron, por el aguijón o dardo divino, como la Santa Teresa de Berninisu amor a dios $y$ por ende, su amor a los hombres por dios (esto es: su amor a ellos en el lugar del dios, guardando ese lugar como lugar-teniente suyo, y no desde luego su amor a Dios en el lugar de - a través de- los hombres, como en San Agustín). Y es que después de todo, y por volver a nuestro inicio, es decir al inicio de este ensayo en el pensar - de este ensayo de pensar- el modo liberal, kantiano ( $y$ en el fondo, como acabo de insinuar, agustiniano) de pensar era cosa fácil de sobrellevar, y de ser admitida por cualquiera.

Nada hay en efecto más común (aunque eso "común" sea justamente la condición de posibilidad de la comunidad) que pensar en el puesto de cualquiera, poniéndose en su lugar. Nada, tampoco, más peligroso, ya que ese "cualquiera" puede fácilmente tornarse en un "uno de tantos» (Man). Heidegger y Hölder-

${ }^{30}$ AsZ; II, 700.
${ }^{31}$ AsZ; II, 702. 
lin, en cambio, exigen que el hombre ame en el nombre de dios, en lugar de él, o sea: en el lugar de su ausencia. Pues el dios presente, el dios que les está presente a los hombres - que está por tanto a su disposición, zur Verfügung- es en cuanto tal incapaz de sufrimiento y sentimiento. $Y$ es que, como avisa gravemente el poeta: no lo pueden todo los Celestes. Ahora bien, ponerse en el lugar del dios sin estar protegido por su mano - como Moisés lo estuvo- significa, nada menos, estar dispuesto a la de-mencia, y a la muerte (Sein zum Tode). Tal el asumido destino del hombre cuando llega a ser el que soporta el extraño "hecho" de que permanezca pendiente (Ausbleiben) là venida de Dios: la estancia en lo excéntrico $^{32}$. Allí, en esa estancia (Stätte), el hombre -el hombre que está a la muerte, abierto a ella como a lo inminente que viene- alcanza su acuidad, su agudeza última (se torna certero y agudo como la punta de una lanza; en alemán: das Ende), el final en el que se concentran y a la vez retiran (sich entziehen: adviértase que también la raíz ent-remite a Ende) todas las posibilidades. Mas esa muerte tiene su incentivo en el amor. Amor estelar al ser lejano, amor al extranjero que yo también me soy, intimior intimo meo.

Extranjero... como dios: como el último dios. Si los hombres tienen historia, ello se debe únicamente a que ese dios pasa fugazmente - está pasando al pasar-, a la vez que el hombre ad-venidero soporta ese paso. Allí, en la muerte que abre el paso (recuérdese que "paso" es también un puerto de montaña), se le abre al pensar una dimensión del ser: la dimensión del secreto-y-misterio del eseyer. Desvelar el ente en la mortalidad humana es así instituir la latencia, la epoché del ser ${ }^{33}$.

Para ello es necesario, a la vez, coraje y desprendimiento: das tapfere Vergessen del espíritu poético y la Gelassenheit del pensador caviloso. Cuando tal copertenencia acaece; cuando, tras largo tiempo, es ereignet sich - das Wahre, entonces nos es lícito presentir - al menos, presentir- que una época del mundo, la era metafísica, está tocando a su fin, y que con ese fin llega también a su término la representación habitual de las cosas como objetos a la mano, reales (wir-

32 M. Heidegger, Hölderlins Hymne "Der Ister". (SS 1942; G.A. 53, 32 s.).

${ }^{33}$ M. HeIDEgGER, Der Spruch des Anaximander. En Holzwege (G.A. 5, 337): "Das frühe Zeichen des Ansichhaltens ist die Aletheia. Indem sie Un-Verborgenheit des Seienden bringt, stiftet sie erst Verborgenheit des Seins. [...] Wir können dieses lichtende Ansichthalten mit der Wahrheit seines Wesens die epoché des Seins nennen". 
klich) a fuerza de ser obra (Werk) humana, demasiado humana. Que también el pensar meditante, y no sólo la filosofía kantiana, tiene su quiliasmo (y más alto por cierto que la "paz perpetua"). Pues, en efecto, también él presiente ya el fin de todas las cosas... de este inicio. Al menos sabemos ya que: «En el otro inicio, el ente no es jamás lo real (das Wirkliche) en el sentido de ser esto 'realmente presente' (Gegenwärtigen). Aun allí donde ello salga al encuentro como teniendo consistencia, tal cosa será lo más efímero para el proyecto originario de la verdad del eseyer. [En el otro inicio,] efectivo (wirklich), es decir, esente, lo es en primer lugar lo recordado, y sigue siéndolo aquello que está presto (das Bereite) " ${ }^{34}$.

Si ello es así, entonces, en el presentimiento de ese otro inicio, y del dios que, en él, está pendiente de venir, las ideas modernas de producto, de interés, de gasto y de provecho dejan ya, ahora, ahora mismo, de tener sentido. Sólo queda el final, sin seguridad alguna (contra la Sicherheit: esa "mala esencia», ese Unwesen de la metafísica), mas también sin sorpresa (contra el quiliasmo apocalíptico... y kantiano). Es un final sencillo, mínimo como das Geringe. Un final como aquel en el que, por caso, un joven de 27 años, Jim Morrison, se aprestó a encontrarse, sin hacerse ilusiones, con su propia muerte. También él disipó seguramente su juventud sin provecho alguno. Ni para él, ni para nadie. Y sin embargo, en su canto, y como respuesta a la voz del amigo, quizá barruntara también él la conjunción, la Fuge del dios venidero y del final de todas las cosas:

\author{
This is the end \\ my only friend, the end \\ of our elaborated plans, the end \\ of everything that stands, the end. \\ No safety no surprise, the end.
}

